\title{
O KYOGEN E A SUA SIMPLICIDADE DE REPRESENTAÇÃO
}

\section{Sakae Murakami}

Kyōgen, teatro cômico, e Nō, teatro lírico-dramático, concretizaram suas formas de representação teatral na época medieval japonesa. Juntos resistiram ao tempo, sendo suas representações levadas ao palco até hoje.

Enquanto o Nō é um teatro de cantos e danças que faz uso de máscaras, o Kyōgen é o teatro de palavras e de expressão corporal, onde as máscaras não são geralmente utilizadas. Com a linguagem altamente poética, o Nō canta contos épicos e lendas, enquanto o Kyōgen, com a sua linguagem coloquial, conta com humor os acontecimentos cotidianos da época.

Com essas características próprias, o Nō e o Kyōgen vêm sendo apresentados num mesmo palco e numa programação única, obtendo um resultado eficaz: o equilíbrio do espetáculo. Após uma tensão quase intolerável provocada pelo Nō, o Kyōgen procura uma reação de "détente" (1) O Nō faz apelo às abstrações mentais mais altas, enquanto o Kyōgen tende a provocar um riso visceral, fundamentado na energia de uma comédia popular (2)

Freqüentemente, esse teatro Kyōgen era relegado a segundo plano, considerado um simples acompanhante do Nō, ou uma parte do teatro Nō. Talvez os homens sempre tivessem atribuido maior seriedade às lágrimas do que ao riso.

Entretanto, após a Segunda Guerra Mundial, com o desenvolvimento dos estudos folclóricos no Japão, o Kyōgen, pelas suas características, atraia atenção dos pesquisadores de vários çampos de estudo, e,consequientemente, o seu valor teatral é revisto e reconsiderado, colocando-o numa posição idêntica à do seu parceiro Nō.

(1). - René Sieffert, Zeami, La Tradition Secrète du Nô Suivie de Une Journée de Nô, Paris, 1960, p. 30.

(2). - Sieffert, p. 30 . 
Kyōgen é um teatro de palavras e de expressão corporal. Nesse teatro, as palavras e a expressão corporal, além de formar o conteúdo da peça, vão criando e estabelecendo outros elementos em cena. E esse fenômeno torna-se possível, por ser ele um teatro que apresenta uma estrutura simples, representado num palco despojado de todo e qualquer cenário.

Vejamos, pois, a peça Kusabira (Os cogumelos) No jardim de certo homem, nascem cogumelos que não são daquela estação. $\mathbf{O}$ homem tenta exterminar esses cogumelos, mas eles sempre voltam a florescer. Extenuado na procura de uma solução, o homem pede auxílio ao yamabushi (bonzo da montanha) para que ele, através das suas fortes orações, faça desaparecer os rebeldes cogumelos. A primeira oração, para alegria do bonzo e do homem, surte o efeito desejado. Entretanto, passados alguns segundos, os cogumelos voltam a florescer com uma força ainda maior, a tal ponto que o homem e o bonzo são obrigados a fugir deles.

Quando Manzō Nomura levou essa peça aos Estados Unidos, a reação da platéia americana foi bem interessante. Ela sentiu nessa peça a guerra do Vietnã (3) Vimos, no entanto, que a peça apenas narra o aparecimento do cogumelo fora da estação. Não seria, justamente essa simplicidade do enredo da peça, com movimentos ricos e palavras diretas, que permitiu a essa platéia o vôo de imaginação, que tendo partido do jardim da casa de um certo homem, vai até os campos de batalha do Vietnã?

A simplicidade do enredo das peças de Kyōgen baseia-se na sua estrutura: tratar-se de uma peça de um ato que possui um começo, um meio e um fim bem definidos, constituindo cada um deles três momentos ou cenas diferentes.

Na primeira cena da peça Buaku (O malvado) - o amo e o empregado Tarō em cena - o amo ordena ao empregado a eliminação do Buaku; na segunda cena - o empregado Tarō e o Buaku - Tarō tenta matar Buaku, mas o seu sentimento humano interfere na realização do ato e não o deixa concluir a sua missão; na terceira cena - o empregado Tarō, o amo e o Buaku - o amo acredita ver o fantasma de Buaku.

Na peça Kamambara (A foice e o suicídio frustrado), na primeira cena - $\mathrm{o}$ marido, a mulher e o apaziguador -0 apaziguador tenta

(3). - Ken Ibaragi, "Kyōgenron Gendai Butai Kyōgen to Shite" (Teoria de Kyōgen, considerado como expressão do Teatro Moderno) in Nihon Koten Geinō 4 Kyōgen Okashi no Keifu (Representação Clássica Japonesa, vol. 4 Kyōgen, Genealogia do Engraçado), Tóquio, 1970, p. 135. 
estabelecer a harmonia entre o marido humilhado pela esposa, por ser preguiçoso, e a esposa enfurecida; na segunda cena - o marido resolve se matar com a foice porque se sente ultrajado em seu orgulho, mas, após inúmeras tentativas, vê como é difícil se suicidar; na terceira cena - o marido e a mulher - a esposa, percebendo a intenção do marido, pede-lhe para não realizar tal itento e o marido, aproveitando a sua situação vantajosa, faz mil exigências à esposa até que a peça termina com a esposa novamente enfurecida.

A primeira cena da peça Suehirogari (O leque) inicia-se com o amo e o empregado Tarō - o amo manda Tarō compar um suehirogari (leque) na capital; a segunda cena - o empregado Tarō e o vendedor arguto - o vencedor, aproveitando a ignorância de Tarō que nem mesmo conhece o termo suehirogari, vende-lhe um guardachuva em vez do leque; a terceira cena - o empregado Tarō e o amo - Tarō recebe uma dura repreensão do amo pelo seu erro, mas ele, através do canto que aprendeu do vendedor, consegue o perdão do amo.

Nas peças acima resumidas, podemos notar um número reduzido de personagens. No Kyōgen, o número de personagens varia entre dois e três, o que sem dúvida reforça a simplicidade dessas peças.

Ligando-se esses momentos à sua representação teatral, vemos que o ator, chegando ao palco, faz o nanori, ou seja, a sua auto-apresentação como personagem teatral, revelando o seu objetivo. Isso reverte num resultado eficaz, justamente devido à ausência de cenário. As palavras não só caracterizam os personagens, mas também definem de uma forma concreta a situação a ser desenvolvida. Não há entradas e saídas constantes dos personagens no palco. O personagem, uma vez instalado ali, permanece durante todo o desenrolar da peça, independente da sua atuação ou não. Se a cena não exige o desempenho do personagem, este se mantem afastado no canto esquerdo do palco (fuebashira) (4). A ausência do personagem fica convencionada dessa forma no Kyōgen. E a peça termina geralmente com os atores se retirando do palco, através da ponte (hashigakari) (5)

As peças de Kyōgen estão intimamente ligadas ao palco denominado Nōbutai (Palco de Nō) Assim. faz-se necessário analisarmos as características deste palco: ele é aberto em três lados, projetado em direção ao público, com o teto alto sustentado por quatro pilares. A sala de espelho (kagami-no-ma), onde os atores se concentram

(4). - cf. planta do Nōbutai

(5). - cf. planta do Nōbutai 
diante de um grande espelho antes de entrar em cena, liga-se a esse palco através de uma ponte (hashigakari) que os conduz ao seu mundo de representação. O único cenário fixo é um soberbo pinheiro pintado no fundo do palco. O pinheiro significa para os japoneses uma longa vida, com a sua cor verde inalterável. Enfim, é esta a árvore que simboliza um evento feliz (6)

Esse palco simples, despojado de qualquer cenário, permite aos atores maior liberdade de movimento e também a liberdade de criar sobre ele as situações e os mais variados objetos por meio de palavras ligadas à expressão corporal. $\mathrm{O}$ ator, junto com a platéia, cria o seu cenário, a situação desejada.

Já dizia Peter Altenberg:

Temos que dizei muito com pouca coisa. O que faz o artista é uma enorme riqueza utilizada com a mais sábia economia. Os japoneses desenham um único ramo florido e ali está toda a Primavera. Entre nós desenha-se toda a Primavera e não se consegue nem mesmo a sensação de um ramo florido. (7)

No Kyōgen, basta a palavra primavera para a platéia criar, junto com o ator, a primavera de cerejeiras.

Possui esse palco outras vantagens. Uma delas é a sua profundidade, vantagem esta que é aproveitada com muita inteligência na segunda cena da peça Bōshibari (Atados na vara) quando os empregados Jirō e Tarō, servindo-se da ausência do amo, vão à adega em busca de saquê. Toda a profundidade do palco é utilizada para dar ao público a impressão de os dois estarem penetrando num outro espaço, diferente do espaço de até então. Ademais, essa profundidade é igualmente propícia para a clássica volta em oval que os atores realizam no palco, a fim de indicar o caminho que leva a um novo espaço. Outra possibilidade deste palco é a ponte (hashigakari) que além de servir de passagem para os personagens que para lá se dirigem às vezes é utilizada como uma área de representação com muito sucesso. A segunda cena da peça Kirokuda (Os bois) inicia-se na ponte quando o empregado Tarō, obedecendo ao seu amo que lhe ordena levar os bois para uma cidade vizinha, utiliza com mestria a estreita passagem da ponte, comunicando dessa maneira, à platéia, um caminho de neve cheio de obstáculos. O espaço de hashigakari, estreito em relação ao palco, contribui

(6). - cf. planta do Nōbutai. O palco é marcado segundo a repre. sentação do teatro $\mathrm{N}_{0}$, mas isso não acarreta nenhum problema ao Kyōgen, pois é um palco despojado de cenários.

(7). - Aldomar Conrado, trad., e org. O Teatro de Meyerhold, Textos e Artigos Selecionados de Meyerhold, Rio de Janeiro, 1969 p. 69. 


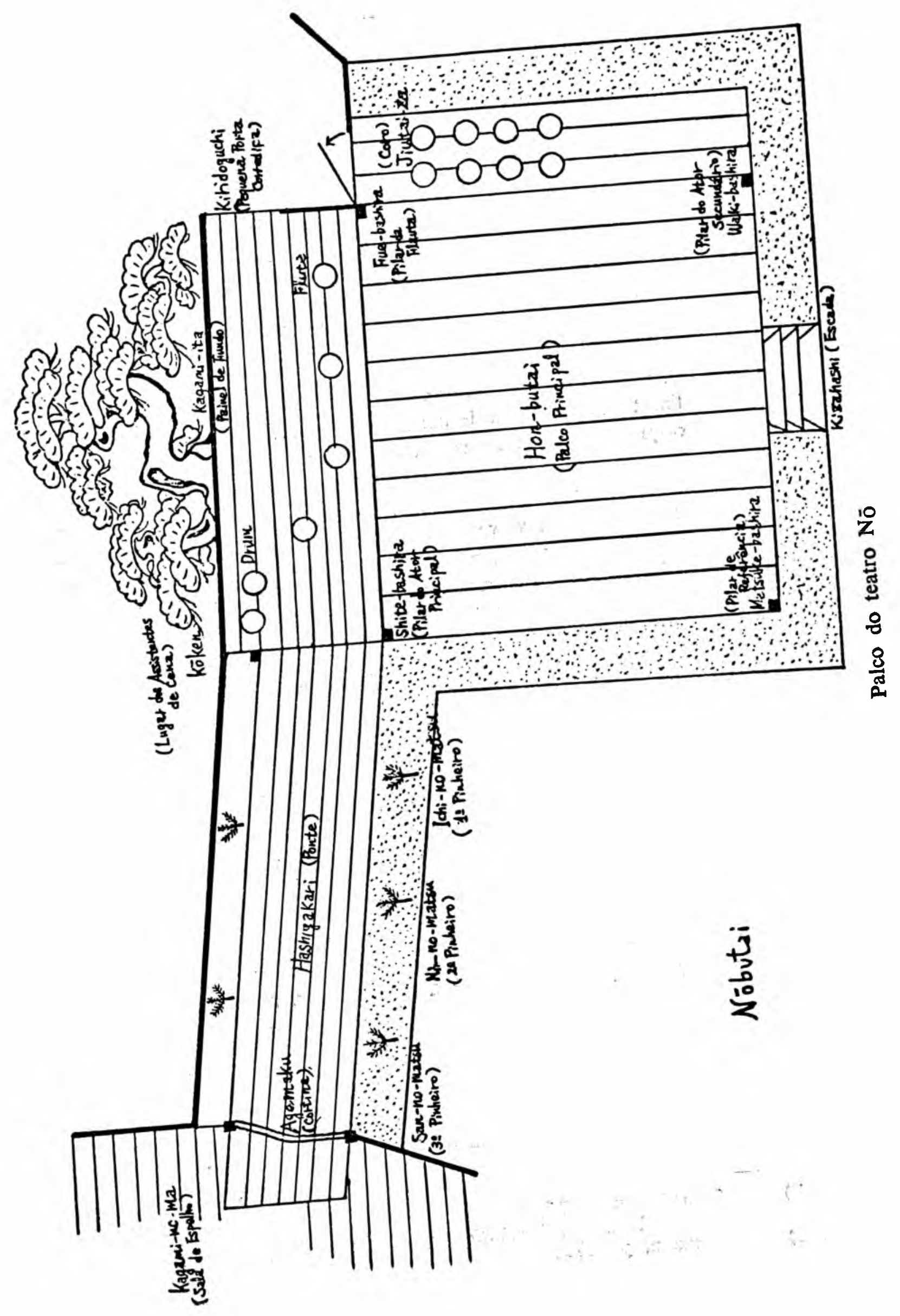


decisivamente para o sucesso da cena. Igualmente, na peça Kamambara (A foice e o suicídio frustrado), o seu primeiro momento tem 0 início no hashigakari. O marido sai da sala de espelho gritando e correndo pela ponte; é seguido pela mulher e, mais uma vez, o comprimento da ponte permite ao marido uma interpretação mais elaborada para nos comunicar o seu profundo desespero.

A representação de Kyōgen não coloca cortina entre o palco e o público. E a luz da platéia permanece acesa durante todo o espetáculo.

Meyerhold, discorria a respeito desses elementos na montagem de $D$. Juan de Molière:

A presença de uma cortina esfria o espectador, mesmo que a cortina tenha sido obra de um grande artista. Tendo vindo para ver o que está por trás, o espectador acolhe esta pintura distraidamente e sem curiosidade. Com a cortina levantada, é preciso o decorrer de um certo tempo para que o público penetre nos sortilégios da atmosfera que envolve os personagens. Se a cortina já está levantada, à sua chegada, o público absorverá a atmosfera da época muito antes do ator entrar em cena... A platéia não deve ficar no escuro nem nos entreatos nem durante o desenrolar da peça. A luz brilhante fornece aos que vieram ao teatro um ambiente de festa. Vendo o espectador sorrir, o ator admira-se como se diante de um espelhho (8).

Exatamente por ser esse palco tão simples e desnudado, fez-se necessária a utilização de elementos que criem os ambientes requeridos - é aí que surge o recurso linguíístico que funciona como meio eficaz na configuração do cenário. Porque envolvem uma "semelhança intrínseca entre o nome e o sentido" (9), as onomatopéias marcam a sua presença nas peças de Kyögen.

Ora, existem do ponto de vista semântico, dois tipos de onomatopéias que se pode distingüir: as onomatopéias primárias (giseigo) e as secundárias (gitaigo). O primeiro é a imitação do som pelo som, o som como "eco do sentido", e o segundo, "em que o som evoca não uma experiência acústica, mas um movimento ou qualquer qualidade física ou moral, geralmente desfavorável" (10)

Na peça Kane-no-ne (O som do sino), na segunda cena, o empregado Tarō vai a Kamakura à procura do melhor som de sino.

(8). - Conrado, p.p. 75,76 .

(9). - Stephen Ullmann, Semântica, cf. Lisboa, 1964, p. 179.

(10). - Ullmann, p. 175. 
Tarō: Hei-Hei-Hei-Hei, Yattona (11). Gwan. Yattona. Gwan

Kore wa ikana koto, korewa waregane dja (12).

(Um, dois e Gwan, e três e Gwan. Que absurdo! Isto é um sino quebrado).

A onomatopéia primária Gwan, som de algo quebrado, permite aos atores, e conseqüentemente ao público, criar sobre o palco um sino quebrado de Kamakura.

Taro: Hei-Hei-Hei, Yattona. Tchim (13).

Kore-wa ikana koto, tiisai ne dja (14).

(Um, dois e Tchim. Ora, Ora, que som tímido).

Tarō: Koon. Kon (15)

Kore wa hibiki no nai katai kane dja. (16).

(Koon. Kon. Isto é um sino duro que não tem vibração).

Tarõ: Hei-Hei-Hei-Hei, Yattona-Yattona. Djan, Mon-MonMon-Mon (17) Yatona. Djan, Mon-Mon-Mon-Mon-Mon.

Satemo, Satemo ne to mōshi hibiki to ii, kono Kenchōji no kane ni ue kosu kane wa gozarumai (18).

(Um, dois e três Djan, Mon-Mon-Mon-Mon. E três! Djan, Mon-Mon-Mon-Mon-Mon. Humm, bem, bem. tanto no som como na vibração, certamente não haverá um sino melhor que este do templo Kenchō)

O que sentimos nesta cena de Kane-no-ne (O som do sino) é o papel dinâmico das onomatopéias primárias que, através do som, vão criando no palco os diferentes sinos: o sino quebrado, o sino de som tímido, o sino duro e o sino majestoso de som perfeito. As onomatopéias primárias criam objetos em cena e a rica expressão corporal do ator ajuda esse processo criativo.

(11). - Interjeição da língua japonesa para expressar o esforço dispensado ao realizar uma ação.

(12) . - Hiroshi Koyama, Nihon Koten Bungaku Taikei $42 \mathrm{Ky} \overline{o g e n s h} \bar{u}$ Diō. (Exposição Sumária da Literatura Clássica Japonesa, vol. 42, Coleção das Peças de Kyōgen 19) Tóquio, 1960, p. 364.

(13). - Som delicado e baixo de coisas metálicas.

(14). - Koyama, Kyogenshu Djō, p. 365.

(15). - Som sem vibração.

(16). - Koyama, Kyogensh $\bar{u}$ Diō, p. 366.

(17). - Som alto e vibrante de coisas metálicas

(18). - Koyama, Kyogensh $\bar{u}$ Djō, p. 367 
Para dar vida e colorido às descrições e às narrações, as onomatopéias secundárias são utilizadas em grande número, dinamizando os diálogos e os monólogos.

Em Nawanai (Corda torcida), Tarō, o empregado, conta a seu amo o encontro que teve com uma criança e uma mulher. Ele ridiculariza ao máximo essas duas personagens utilizando as onomatopéias como tchigari-tchigari-tchigari, que expressa o defeito no andar da mulher; nyorori-nyorori-nyorori, o andar lento e deselegante da mulher; hyorori-hyorori, a aparência extremamente magra da criança; kuru-kuru-kuru-kuru, os cabelos embaraçados da criança; koso-kosokoso-koso, o movimento silencioso e apressado da criança. A história termina com o amo extremamente irritado, pois essa criança e a mulher são justamente a sua esposa e o seu filho, fato que Tarō desconhecia (19)

O espaço, o tempo e o ritmo são igualmente determinados pelas palavras neste teatro. As palavras criam a noite, o dia, e esse palco despojado de cenários ora é a casa do amo, ora é a casa de Tarō, ora é a capital. Para essa mudança de espaço, é necessário apenas o movimento em oval que $o$ ator realiza no palco e uma palavra indicativa do lugar, ou às vezes nem mesmo isso. Na peça Bunzō (O difícil estratagema de memória), Tarō conta a seu amo as novidades da capital, com o intuito de acabar com o mau humor do seu senhor. Começa a contar pela visita que ele fez à casa de seu tio, e passa a descrever um doce delicioso que alí saboreou, de cujo nome não se lembra. Após um esforço de memória, ele consegue recordar que o nome do doce aparecia num livro de história do seu amo. Tudo isso decorre na casa de Tarō, onde o seu senhor havia ido procurá-lo. Entretanto, no momento em que $o$ amo ordena que Tarō procure o livro, $o$ o espaço passa a ser a casa do senhor. O próprio desenrolar da peça vai determinado o espaço. A ausência de cenário permite ao Kyōgen essa liberdade.

Quanto ao ritmo, muitas vezes bastam as palavras sorori-sorori to mairō (irei sem pressa) ou isoide mairō (vou depressa) para determinar num único ritmo predominante na peça, a rapidez ou a lentidão.

O que podemos concluir de todas essas observações é que realmente não se pode pensar num espetáculo de Kyōgen desligado do seu palco, pois é esse palco, com suas características próprias, despojado de cenário, que permite a liberdade de as palavras agirem com toda a sua força, sem nenhum obstáculo visual. Também contribui para o sucesso da apresentação a própria estrutura simples das peças de

(19). - Koyama, Kyogenshu Djō, p.p. 276-78. 
Kyōgen, e o seu número reduzido de personagens, por sua vez, permite à platéia concentrar a sua atenção sobre todos os personagens para poder criar junto com eles os diversos elementos de cena. Manzō Nomura que assistiu à representação de $O$ Inspetor-Geral de Gógol - no qual havia um número muito grande de atores em palco - pelo Teatro de Arte de Moscou, na ocasião em que ele esteve no Japão, dizia aos que lhe perguntavam a sua opinião: "Não, não gostei muito. Tudo é demais" (20)

\section{BIBLIOGRAFIA}

Conrado, Aldomar, trad. e org., O Teatro de Meyerhold, Textos e Artigos Selecionados de Meyehold, Editora Civilização Brasileira S/A, Rio de Janeiro 1969.

Ibaragi, Ken, Kyŏgenron Gendai no Butai Hyŏgen to Shite (Teoria de Kyŏgen, Considerado como Expressão do Teatro Moderno) in Nihon Koten Geinŏ 4 Kyŏgen Okashi no Keifu (Representação Clássica Japonesa, 4, Kyogen Genealogia do Engrą̧ado), Heibonsha, Tóquio, 1970, p.p. 125-145.

Koyama, Hiroshi, Nihon Koten Bungaku Taikei 42/43 Kyōgnesh $\bar{u}$ Djō/Ge (Exposição Sumária da Literatura Cláásica Japonesa 42/43, Coleção das Peças de Kyŏgen 1\%/2\%), Sanseidŏ, Tóquio, 1960.

Manzŏ, Nomura. Kyŏgen no Michi (O caminho de Kyŏgen), Wanyashotem, Tóquio, 1968.

MacKinnon, Richard N., Selected Plays of Kyŏgen, Komiyama Printing Co., Tóquio, 1968.

Miyake, Tokuro, Kyŏgen no Midokoro (Promessas de Kyŏgen), Wanyashoten, Tóquio, 1975.

MacKinnon, Richard, "Notes on the Kyŏgen", in Asian Drama - A Collection of Festival Papers, May, 1966, p. p. 21-29.

Sieffert, René, Zeami, La Tradition Secrète du Nô Suivie de Une Journée de Nô, Gallimard, Paris, 1960.

Toita, Michizō, Kyōgen, Rakurakushita Kamigami no Henbo (Kyŏgen a transformação dos deuses que decaíram), Heibonsha, Tóquio, 1974.

Ueda, Makoto, "Japanese Idea of a Theatre", in Modern Drama, IX, 4 (februa:y, 1967), p.p. 348-357

Ullmann Stephen, Semântica, Fundação Calouste Gulbenkian, Lisboa, 1964 Yokomichi, Mario, Nŏ to Kyŏgen no Sekai (O Mundo de Nô e Kyŏgen), Heibonsha, Tóquio, 1973.

(20). - Ibaragi, p. 132. 